\author{
Md. Tariqul Islam ${ }^{1}$ \\ A.S.M. Woobaidullah ${ }^{1^{*}}$
}

Manuscript Received: 28 April 2019

Accepted: 26 October 2019

1Department of Geology, University of

Dhaka, Dhaka-1000, Bangladesh

${ }^{*}$ Corresponding author

Email: woobaid.du@gmail.com

\section{Surface Resistivity Sounding and Borehole Data Analysis for the Evaluation of Aquifer Characteristics of Southern Districts Barguna and Patuakhali, Bangladesh}

\begin{abstract}
The study delineates the aquifer system of the study area and determines the extension of potential fresh water aquifer and suitable locations for groundwater development through geophysical electrical resistivity method. Vertical electrical sounding with Schlumberger electrode configuration, a method for surface resistivity measurement, has been used for data collection. Resistivity data along with borelog data analyses are used for this investigation. Lithological cross section analyses show that sand and clay dominated lithology with frequent facies changes occur throughout the area and also show an aquifer system similar to the three-tier aquifer system proposed by Aggarwal for coastal area of Bangladesh. This study reveals the presence of three aquifers. 1staquifer occurs at a very shallow
\end{abstract}

\begin{abstract}
depth at some places $<5 \mathrm{~m}$ and thickness of the aquifer varies $10-70 \mathrm{~m}$ all over the region, and shows very low resistivity value indicating saline pore water. Average depth to the $2^{\text {nd }}$ aquifer ranges from $60-70 \mathrm{~m}$ and also contaminated by saline water. In few places of $2^{\text {nd }}$ aquifer resistivity values more than $20 \Omega m$ suggest some fresh water pockets. Depth to the 3rd aquifer that spreads all over the study area is more than $220 \mathrm{~m}$ at maximum part of the area. Only potential fresh water aquifer is the 3rd or deep aquifer, but low resistivity values of this aquifer at Patharghata and small portion of Kalapara and Rangabali Upazilas hint that there may have saline water intrusion. More precise information for this complex geological set up require greater number of sounding points.
\end{abstract}

Keywords: Resistivity, Aquifer, Aquitard, Vertical Electrical Sounding

\section{Introduction}

In a densely populated country like Bangladesh, supplying of water to the people with sufficient quantity of appropriate quality is one of the most crucial challenges of our present time. "Drinking water from natural sources in coastal Bangladesh has become contaminated by varying degrees of salinity due to saltwater intrusion from rising sea levels, cyclone and storm surges, and upstream withdrawal of freshwater" (Khan et al., 2011). The study area, that includes Patuakhali and Barguna Districts, is a tidal floodplain area (Figure 1) and has shallow aquifer contaminated by saline water. This is a major problem for drinking water sources in the study area. Groundwater EC values vary from 31,000 to 43,300 and 39,000 to $44,600 \mu \mathrm{S} / \mathrm{cm}$ in dry and wet seasons, respectively, in the 1st aquifer (shallow). The maximum EC value of dry and wet seasons are measured at 43,300 and $44,600 \mu \mathrm{S} / \mathrm{cm}$, respectively, at Patharghata (Zahid, et al., 2016).

The geography of Bangladesh is dominated by three great rivers Ganges, Brahmaputra-Jamuna and M eghna and a dense network of branches, distributaries and connecting channels. The combined area of the drainage basin of the three rivers is about 16 million $\mathrm{km}^{2}$ and carries a sediment load of about 1.67 billion tons (Imam, 2005). The aquifer formations of Bangladesh are developed by the fluvial and estuarine unconsolidated sediments of Pleistocene to Recent age.

The aim of Hydro-geological study of this coastal region is to identify the aquifer of the region including its seasonal variation. As country's third sea port Payra sea port is implementing at this region, there is a major impact of this project on socio-economic life to be oncoming including the effect of tourism at the area. The study is also intended to identify the availability of fresh ground water, which would be required for forthcoming agitation such as fresh water scarcity, salinity intrusion, irrigation difficulties etc. This study uses geophysical data analysis and interpretation for hydrogeological investigation. Geophysical investigations are taking measurements at or near the earth surface which are influenced by the internal physical properties. The main objective of 
the geophysical investigation is to delineate aquifer system of the study area. The specific objectives of the investigation are:

i. Identification of different geological layers along with its vertical and horizontal extent minimum up to the depth of $300 \mathrm{~m}$ within the study area,

ii. Identification of potential fresh water aquifers of up to the depth of $300 \mathrm{~m}$ along with their depth, extent and thickness.
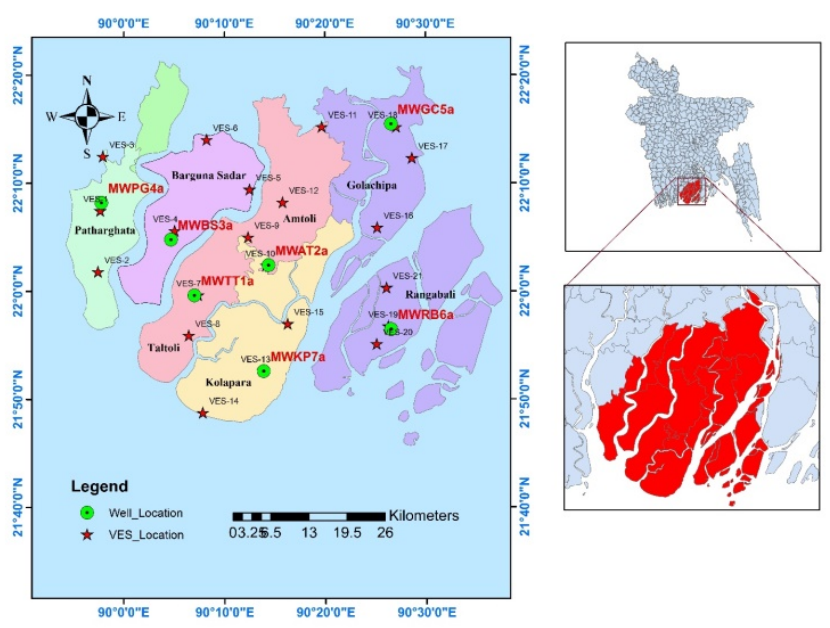

Figure 1: VES Points and Borehole Locations in the Study Area

\section{Methodology}

Geo-electrical resistivity survey has long been used for ground water survey and the method is found to be very successful. As a preliminary step for the development of ground water, geo electrical resistivity survey proved to be very effective (Bugg and Lloyed, 1976; Serres, 1969; Woobaidullah et al., 1996). In resistivity method, artificially generated electric currents are introduced into the ground and the resulting potential differences are measured at the surface. Rocks usually conduct electricity due to the electrolytic conduction of pore fluid interconnection (Keller and Frischnecht, 1996). The arrangement of current and potential electrodes on or in the ground for the purpose of making an electrical survey is called electrode configuration. The current electrodes are generally placed on the outside of the potential electrodes (Kearey and Brooks, 1984). Based on the position of current or potential electrodes and variation in distance between them, a variety of electrode configurations are possible of which some are mentioned below: 1) Wenner configuration 2)
Schlumberger configuration 3) Dipole-dipole configuration. The electrical resistivity survey involves electrical sounding using Schlumberger configuration with McOHM (Model-2115) resistivity meter. Schlumberger proposed this configuration in 1916. This is the only array to rival the Wenner in availability of interpretational material. The Schlumberger configuration is widely used in measuring the earth resistivities, which is designed to measure approximately the potential gradient. In this array four electrodes are placed symmetrically from the center, where the outer two electrodes are current electrodes. The current electrodes ( $A$ and $B$ ) are spaced much further apart than the potential electrodes ( $\mathrm{M}$ and $\mathrm{N}$ ) (Figure 2). The distance between the potential electrodes is $1 / 5$ to $1 / 10$ th of the current electrodes.

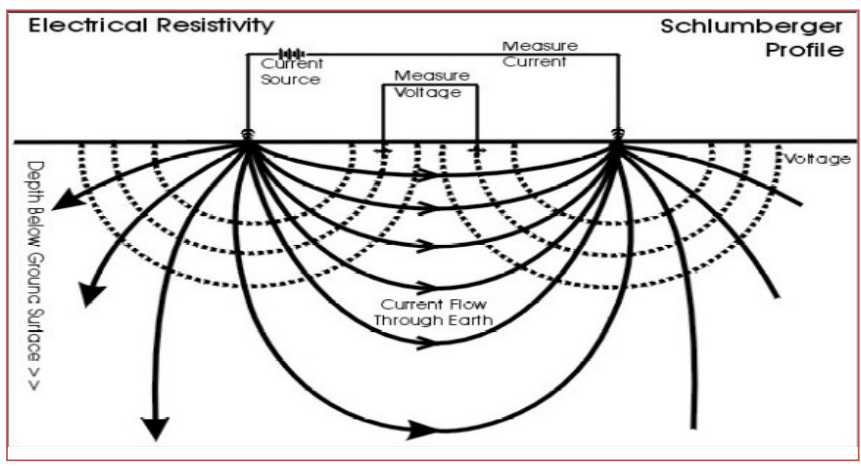

Figure 2: Schlumberger Configuration

In depth probing the potential electrodes remain fixed while the current electrodes spacing is expanded symmetrically about the center of the spread. For large values of current electrode separation, it may be necessary to increase the potential electrode separation in order to maintain a measurable potential within the accuracy limit of the instrument. In case of lateral exploration, the electrode spacing remains fixed and the whole array is moved along the line in suitable steps (Figure-02). For Schlumberger configuration the apparent resistivity ( $\rho a)$ is determined by the following equation (Telford et. al., 1976):

$$
\rho_{a}=2 \pi\left(L^{2}-I^{2}\right) / 2 I \times \Delta V / I
$$

Where, $L=$ half of the current electrode separation.

I =half of the potential electrode separation.

$\Delta \mathrm{V}=$ measured potential difference.

I =supplied amount of current. 
Vertical Electrical Resistivity Soundings (VES) have been carried out in the study area with an objective to follow the subsurface lithology variation, determine aquifer geometry, and possible thickness and extension of the aquifer and aquitard.

21 VES of Schlumberger Configuration with $600 \mathrm{~m}$ $(A B / 2=300 \mathrm{~m})$ spread are planned to execute in the study area. The resistivity measuring equipment "Resistivity Meter" for the survey is kept at the center of the array. The station locations are random but covering the whole study area. The layout is done along a straight line from the center. The half of the current electrode separation $(A B / 2)$ as selected is $1 \mathrm{~m}, 2 \mathrm{~m}, 4 \mathrm{~m}, 6 \mathrm{~m}, 8 \mathrm{~m}, 10 \mathrm{~m}, 12 \mathrm{~m}, 15 \mathrm{~m}, 20 \mathrm{~m}, 25$ $\mathrm{m}, 30 \mathrm{~m}, 40 \mathrm{~m}, 50 \mathrm{~m}, 60 \mathrm{~m}, 80 \mathrm{~m}, 100 \mathrm{~m}, 120 \mathrm{~m}, 150$ $\mathrm{m}, 200 \mathrm{~m}, 250 \mathrm{~m}$ and $300 \mathrm{~m}$ in each side of the station. The potential electrode spacing is selected depending on the measurement of potential difference. The potential electrodes are spaced as 0.5 $\mathrm{m}, 1 \mathrm{~m}, 2 \mathrm{~m}, 5 \mathrm{~m}, 10 \mathrm{~m}$ and $20 \mathrm{~m}$ in each side of the center. If large variations are observed in the subsequent values of apparent resistivity then the measurements are repeated to find the steadiness in the measurements.

\section{Interpretation}

The resistivity sounding data are plotted in the software named IXID to see the smoothness of the data as well as for interpretation. The estimated model obtained through software based matching is taken to be the subsurface united geo-electric model of respective VES point (Figure 3(a) and 3(b)). This model is then compared and calibrated to the existing bore log data on or close to the VES point to obtain the final geo-electric model (Figure 3(a) and $3(b))$.

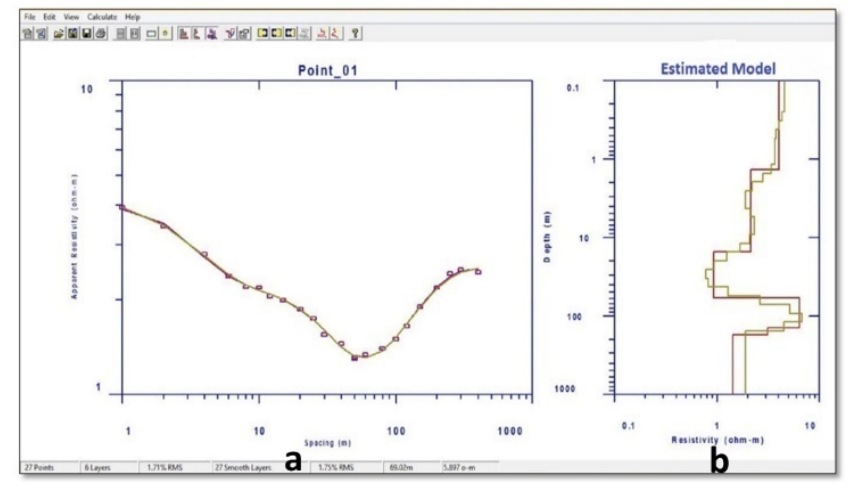

Figure 3: (a) Sounding Curve of VES Point 01 and (b) its Estimated Geo-electric Model
For comparison between bore log and vertical electrical sounding (VES), it is essential that the location of the bore log should be very close to the VES location point. It has been realized that for making a comparison using a generalized lithologic succession, resistivity sounding is a quite efficient method and therefore it can be considered as a good means for the evaluation of subsurface geological condition particularly in terms of aquifer, aquitard etc.

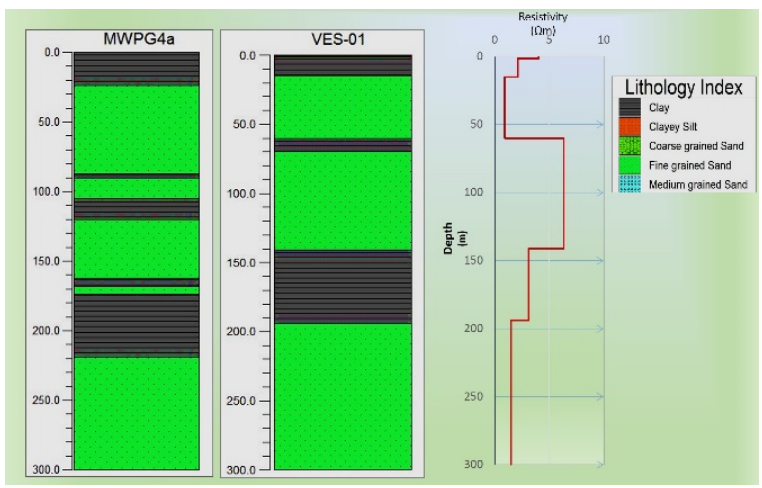

(a)

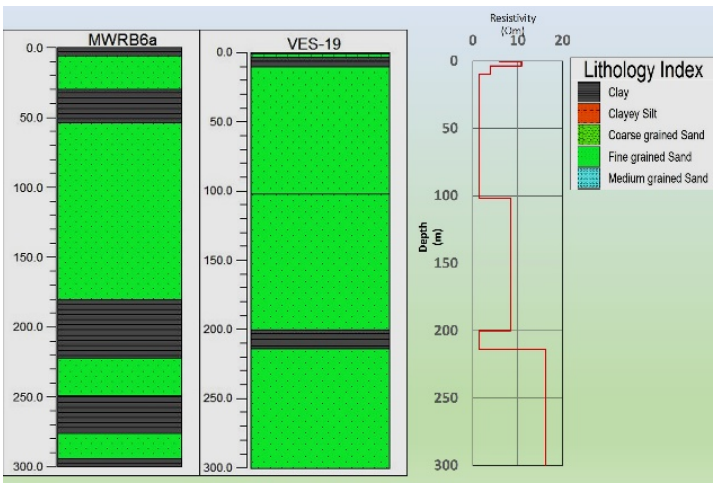

(b)

Figure 4: Lithological Comparison between (a) Existing Borehole M WPG4a and VES-01; and (b) Existing Borehole MWRB6a and VES-19

After comparing the VES data and nearest bore log data, following resistivity ranges have been established against different rock types (Table: 1).

Table 1: Resistivity Range of Different Rock Types

\begin{tabular}{|l|l|}
\hline Resistivity Range $(\Omega-\mathrm{m})$ & Corresponding Rock type \\
\hline $6-15$ & Top Soil \\
\hline $1-6$ & Clay \\
\hline $6-9$ & Clayey Silt \\
\hline $9-20$ & Fine grained Sand \\
\hline $20-100$ & Medium grained Sand \\
\hline$>100$ & Coarse grained Sand \\
\hline
\end{tabular}




\section{Lithological Interpretations}

Four lithogical cross sections A-A', B-B', C-C' and DD' are drawn to observe the vertical and lateral variation of the rock types in the study area. Directions of these cross-section are shown in the Figure 5.

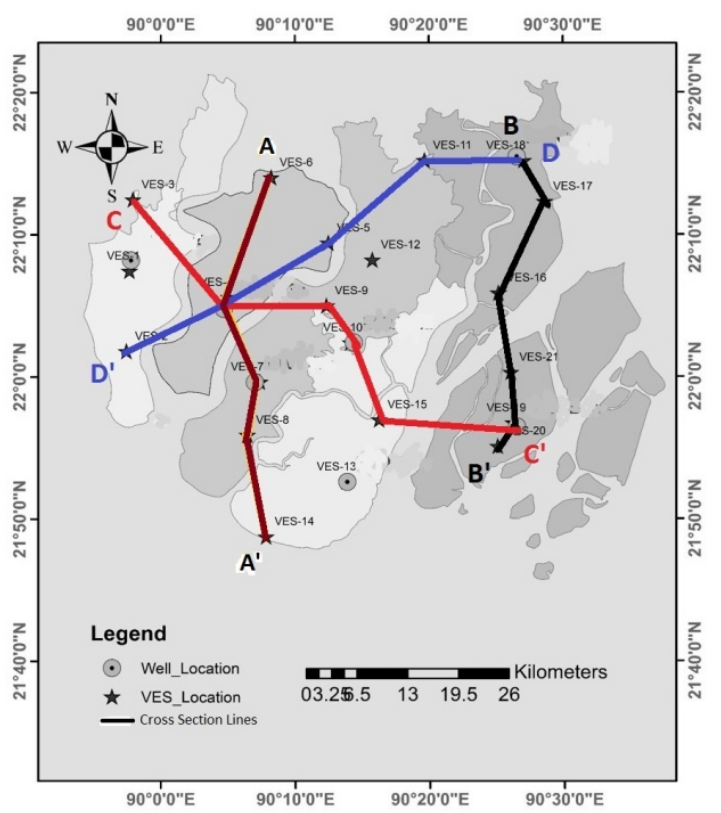

Figure 5: Selected Lines through the Corresponding VES Points with Respect to their Position for Lithological Cross Section

\section{Cross section along $A-A^{\prime}$}

Cross section $A A^{\prime}$ along North-South covers five VES points named VES-06, VES-04, VES-07 VES-08 and VES14 shows non-uniformity in the lithological distribution especially in the grain size (Figure 6). Several tidal rivers and channels are in the middle of these VES points such as, Pyra River between VES-4 and VES-07, Andharmanik River between VES-08 and VES-14. Surface is covered by $1-1.5 \mathrm{~m}$ thin soil layer along the cross section. A uniformly thick clay layer with 10-12 $\mathrm{m}$ thickness is found below the top soil layer of Barguna Sadar Upazilla. But, at the same depth at Taltoli and Kolapara Upazilla a sand layer of similar thickness is found. A major facies change occurs between VES-04 and VES-07 at the present position of Pyra River and a thick clay layer exists below this sand layer and thickness of clay layer increases towards south. Further south, textural change occurs to the lithology leading to a thick silty clay unit. Alternating sand and clay layers occur in the subsurface. A great lateral variation in the grain size of sand is observed and finer sands are in the northern part, medium and coarser sands at the middle and medium grains at southern part of the cross section. Inter bedded clay layers are non-continuous and indicate frequent changes in the depositional environment.

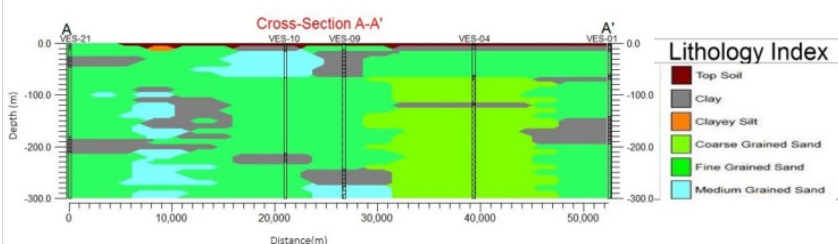

Figure 6: Lithological Cross Section along A-A'

\section{Cross section along B-B'}

Cross section along BB' across six points VES-18, VES17, VES-16, VES-21, VES-19 and VES-20 runs approximately north to south in the eastern part of the study area over Golachipa and Rangabali Upazilla (Figure 7). A 5-10 m thick clayey silt layer is underlying the top soil and almost continuously and uniformly distributed over the northern part (Golachipa) of the cross section. Top soil and clay layer are absent over a large area between VES-16 and VES-19 where Golachipa River flows dividing Golachipa and Rangabali Upazilla. Underlying sediments are dominated by fine sand and medium sand has found in the middle portion of the section below 70 to $80 \mathrm{~m}$ depth and a little amount of coarse grained sand is observed under VES-17 at greater than 100-120 m depth. Lateral lithology distribution along the cross section indicates that upper clay layers are discontinuous and alternate with the sand layers. A continuous clay layer is found at depth around 170 to $180 \mathrm{~m}$ which is thin at northern part and gradually get thicker towards south. Thickness of the clay layers varies from 10 to $40 \mathrm{~m}$. A continuous sand layer of varying grain size at the depth above $200 \mathrm{~m}$ may act as potential zone for groundwater development.

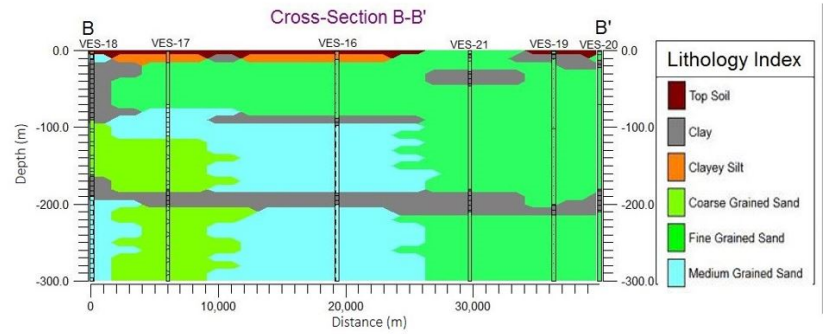

Figure 7: Lithological Cross Section along B-B'

\section{Cross Section along C-C'}

Cross section along $C^{-} C^{\prime}$ is from northwest to southeast goes through six VES points, VES-03, VES- 
04, VES-09, VES-10, VES-15 and VES-20 (Figure 8). First clay layer beneath the top soil is continuous from northwest part to central part along the cross section and is absent in the south. Thickness of this clay layer is about $40 \mathrm{~m}$ to the northwest and middle part but very much thin $(5-10 \mathrm{~m})$ between these two thick portions. Cross section shows abrupt change in the underlying lithology both laterally and vertically. Distribution of underlying sediments especially clay layers frequently changes throughout the section. Thus any trend for thickness and grain sizes cannot be establish. Subsurface lithology is dominated by sand particularly fine sand. A thick deposition of coarse sand is spotted at $65 \mathrm{~m}$ depth with inter-bedded thin clay layer. Clayey silt deposition is coexisted with clay layer at $130 \mathrm{~m}$ depth in the northern part of the section.

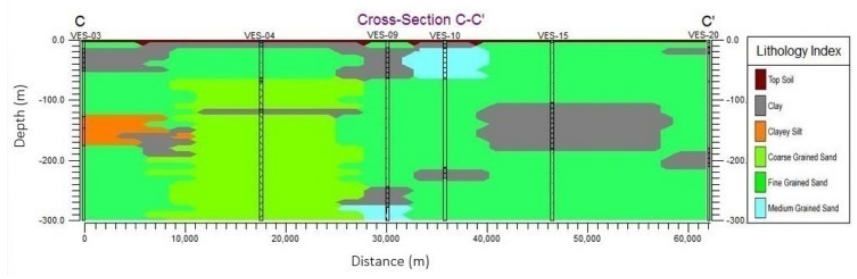

Figure 8: Lithological Cross Section along C-C'

\section{Cross section along D-D'}

Cross section from northeast to west runs over following five sounding points, VES-18, VES-11, VES05, VES-04 and VES-02 (Figure 9). Underlying lithology is predominantly composed of alternating sand and clay layers with varying thickness. Clay layer below top soil unit is almost $80 \mathrm{~m}$ thick in the northeast part and decreases to the western direction. The layer is discontinuous at several places and shows no uniformity in thickness. Such uneven distribution is also found for other underlying layers. Subsurface sand dominated lithology shows great variation in the sand grain sizes. It displays medium to coarse to fine grained sand from northeast to western direction.

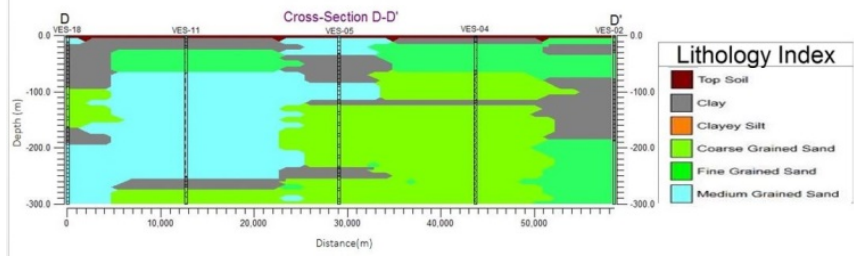

Figure 9: Lithological Cross Section along D-D'

\section{Fence Diagram}

Fence diagram (Figure 10) provides an aerial observation in the lateral and vertical variation in the subsurface lithology of the study area.

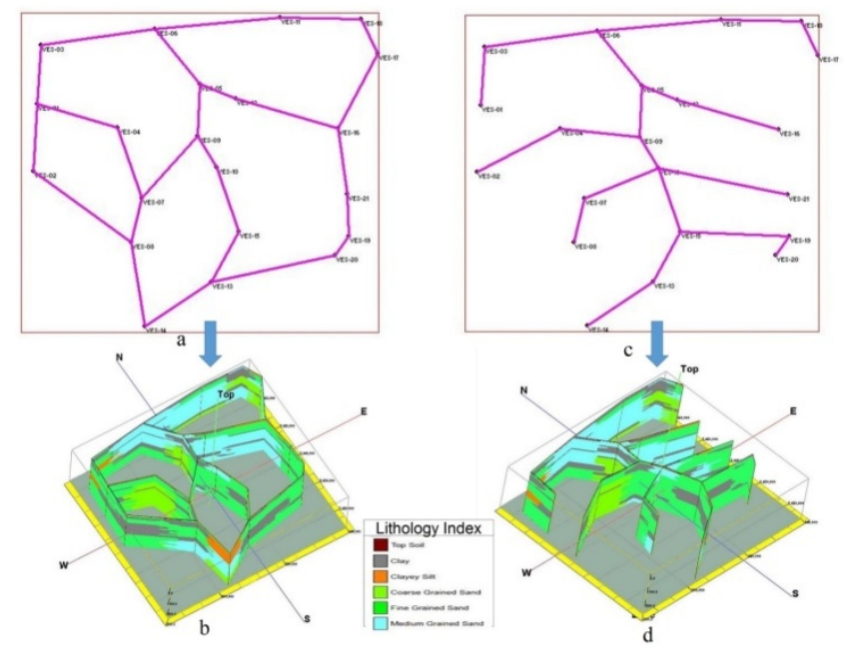

Figure 10: Selected Lines Trough the Corresponding VES Points with Respect to their Position for the Construction of Fence Diagram; ( $a$ and $c$ are Fence Designer $M$ ap and $b$ and $d$ are their Respective Fence Diagram)

Subsurface of the study area is composed of alternating sand and clay layers. Only a little amount of clayey silt is found at shallow depth in the eastern region of the study area. Subsurface of the northern part of Borguna Sadar, Amtoli and Golachipa Upazila is dominated by fine sand. A few locations such as VES04, VES-05 (Central part of Barguna Sadar) and VES-18 (Golachipa) have coarse sand in subsurface lithology with interbedded thin clay layers. Rest of the area predominantly composed of fine sand with little amount clay.

\section{3- Dimensional Model and Block Diagram}

3D modeling and block diagram of subsurface lithology has been manipulated by using RockPlot3D in Rockworks. 3 dimensional model (Figure 11) represents very complex subsurface sediment distribution. Sand and clay alteration is highly variable even within a short distance. Northeast view of 3D block diagram [Figure 11 (a)] represents a thick pile of medium sand which produces a stair like projection towards east. Figure 11 (b) shows that western part has a 100m thick clay layer (approximately 100 m-200 $m$ depth) unlikely to other areas. All the views of block diagram illustrate that above $200 \mathrm{~m}$ depth clay deposition is discontinuous and identification of sand and clay layers are in vague. Only one clay layer (180- 
$200 \mathrm{~m}$ depth) has been found to be laterally extend all over the area, but has two discontinuous part, one is in the northern part [Figure 11 (a) and (b)] and southwestern corner [Figure 11 (d)].

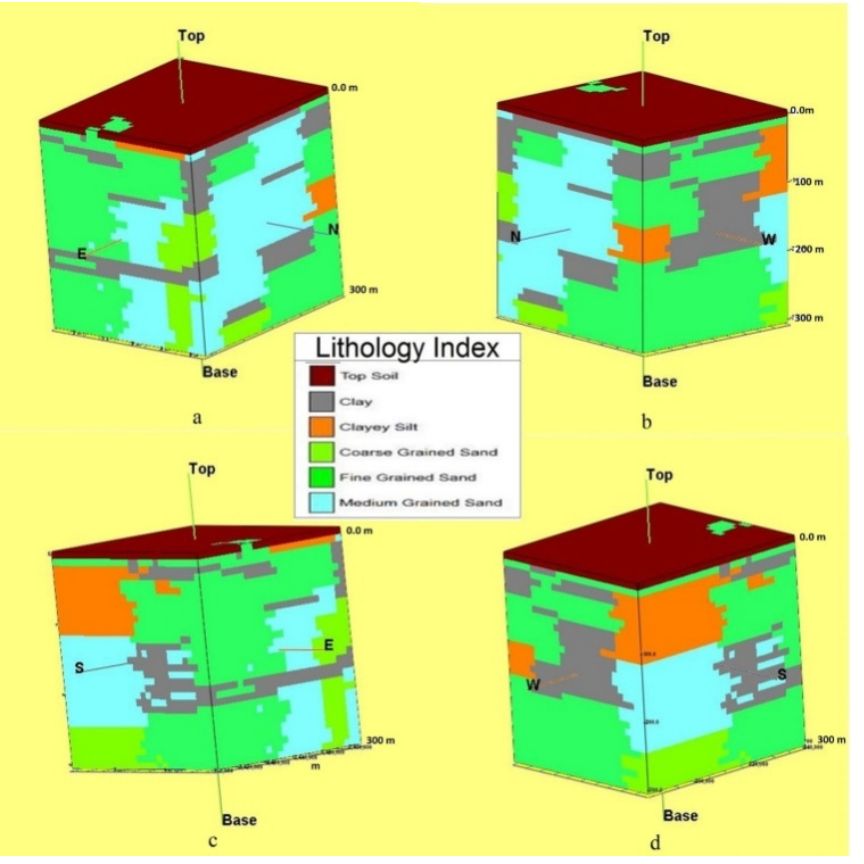

Figure 11: 3-D Block Diagram Shows Subsurface Lithological M odel of the Study Area; a) Northeast View, b) Northwest View, c) Southeast View, d) Southwest View

\section{Hydro-stratigraphic Analysis of the Study Area}

From the existing borehole data (300 m depth) analysis and lithological interpretation of the investigated VES $(300 \mathrm{~m})$ it is possible to develop a hydro-stratigraphic model for the area. From the lithological analysis hydro-stratigraphy of the study area is divided into aquifer and aquitard. Below top soil multiple layers of aquifer and aquitard is observed.

\section{$\mathbf{1}^{\text {st }}$ Aquifer}

1st aquifer occurs at a very shallow depth and just after few meters depth in some region and can also be designated as shallow aquifer (Figure 12). Resistivity distribution of this aquifer is very low which describes the occurrence of saline water. Resistivity is $<3 \Omega \mathrm{m}$ in the eastern (Kalapara, Rangabali and Galachipa Upazilla) and western (Patharghata Upazilla) territory of the study area. Aquifer occurs at very shallow depth $(<5 \mathrm{~m})$ in Western and Northwestern part (Barguna Sadar, Patuakhali Sadar, Patharghata Upazilla) and bit by bit gets further (about $15 \mathrm{~m}$ ) towards the Eastern and southeastern portion of the study area.
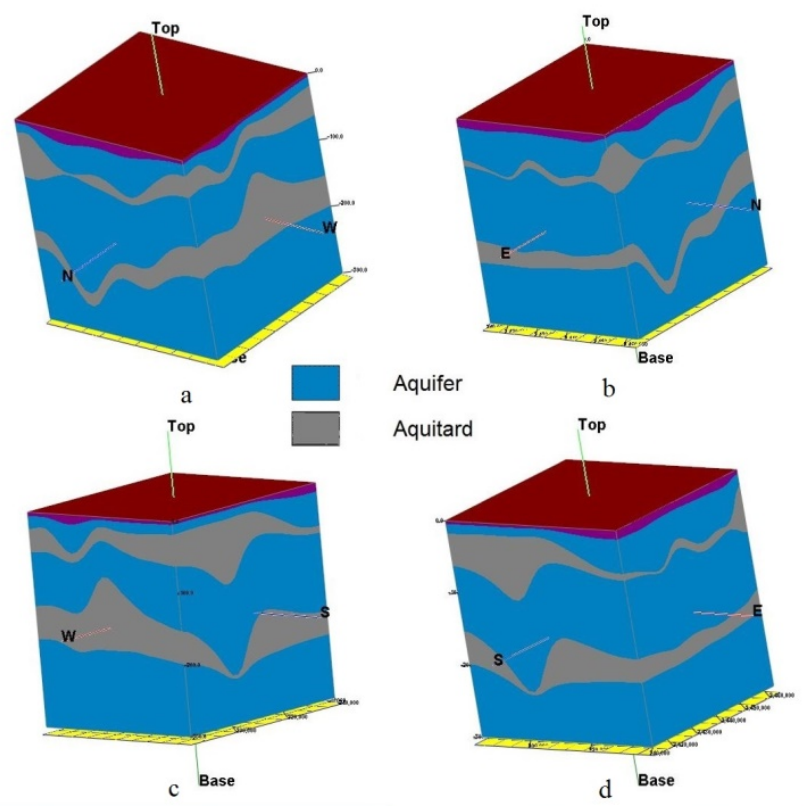

Figure 12: Hydro-stratigraphic M odel of the Study Area; a) Northwestern View, b) Northeastern View, c) Southwestern View, d) Southeastern View

\section{$2^{\text {nd }}$ Aquifer}

Depth of 2 nd aquifer varies from less than $40 \mathrm{~m}$ to more than $90 \mathrm{~m}$. Depth for $2 \mathrm{nd}$ aquifer is $60-70 \mathrm{~m}$ in most of the area (Figure 12). Because of the leaky nature of the upper 1st aquitard, 2nd aquifer shows very low resistivity except vertical electrical sounding points VES-11, VES-12, VES-16, VES-17 and VES-18 of Patuakhali and northern part of Galachipa Upazilla. Resistivity of 2 nd aquifer along the mentioned area is near $20 \Omega m$ (Table 1). Thickness of the aquifer is also greater in this portion of the study area and depth to the bottom surface of the aquifer is also $>220 \mathrm{~m}$. 2nd aquifer at greater depth might be a source of fresh ground water for limited extraction.

\section{$3^{\text {rd }}$ Aquifer}

Depth to the 3rd aquifer at the south central region is less than $170 \mathrm{~m}$. Depth is about approximately $220 \mathrm{~m}$ throughout the territory. Thickness of the aquifer is arbitrary as of investigation is around $300 \mathrm{~m}$ and base of the aquifer could not be identified (Figure 12).

Resistivity contour map of 3rd aquifer (Figure 14) displays low resistivity $(<10 \Omega \mathrm{m})$ at VES-01, VES-02, VES-03, VES-06, VES-13, VES-19 and VES-21, providing a clear indication of salinity intrusion at these part of 3rd aquifer. According to the corresponding location of the VES data (Figure 3) whole Patharghata Upazilla and some portions of Kolapara and Rangabali Upazilla 
are unsuitable for fresh groundwater development. Low resistivity in some cases may arise from instrumental limitation or presence of clay pocket in the aquifer. 3-Dimensional distribution of third aquifer is shown in figure 13 where depth to the basement is not the base of the aquifer rather it shows final depth to the measurement.

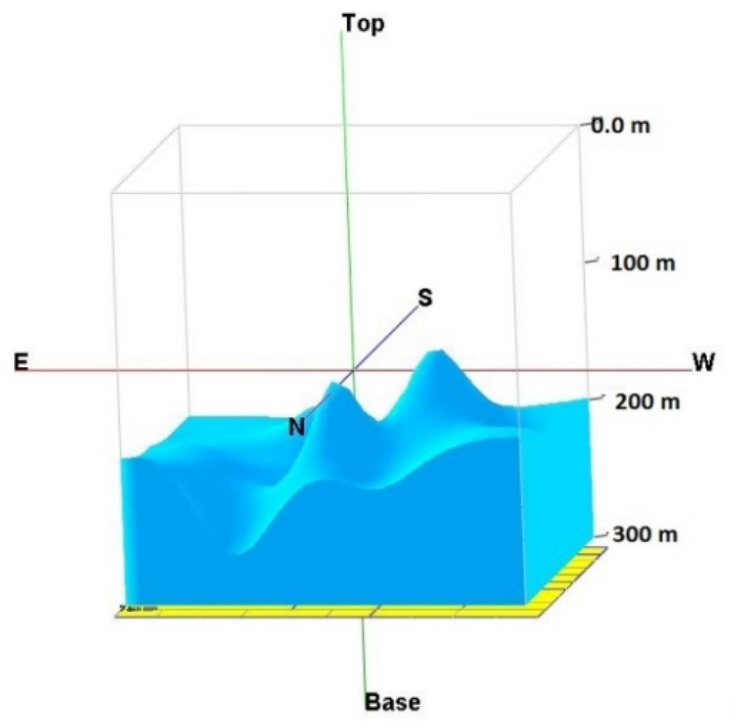

Figure 13: 3- Dimensional M odel shows the upper surface of the 3rd Aquifer of study area

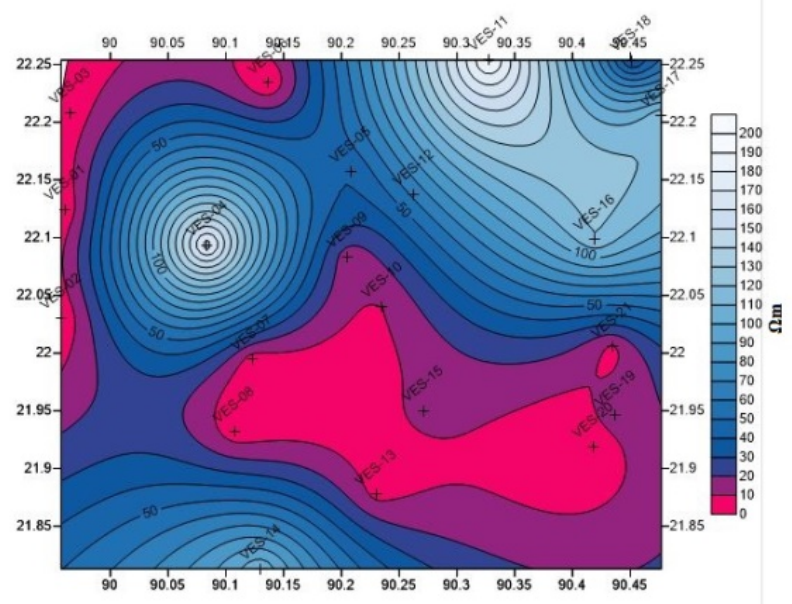

Figure 14: Resistivity Contour MapShows Lateral Resistivity Distribution of $3^{\text {rd }}$ Aquifer

\section{Conclusion}

Existing borelog data (300 m depth) analysis and lithological interpretation of the investigated Vertical Electrical Sounding (VES) results provide a hydrogeological set up which is similar to the traditional three-tier coastal aquifer system proposed by Aggarwal et al. (2000) for coastal area Bangladesh.
Low Resistivity value of first two aquifers confirms salinity intrusion to the aquifers. Lithology distribution of 1st aquitard between 1st and 2nd aquifer is uneven, discontinuous and leaky which allows invasion of saline water from 1st aquifer to 2nd aquifer. 3rd aquifer or deep aquifer is the only potential zone for groundwater development.

$1^{\text {st }}$ aquifer initiates at a very shallow depth at some places which is $<5 \mathrm{~m}$ and thickness of the aquifer is 10$70 \mathrm{~m}$ all over the region and shows very low resistivity value because of high salinity in the ground water. Average depth to the 2nd aquifer is $60-70 \mathrm{~m}$ and also contaminated by saline water. Only a few places shows resistivity more than $20 \Omega \mathrm{m}$ at the depth of $2 \mathrm{nd}$ aquifer below VES-04, VES-05, VES-10, VES-12, VES-16 and VES-17. It indicates presence of some fresh water pocket zone shallower than mentioned 3rd or main aquifer.

Average starting depth of 3rd aquifer is more than 220 $m$ at maximum part of the study area and spread all over below the subsurface. Two low resistivity zones have been identified at the depth of 3rd aquifer at whole Patharghta Upazila and little portion of Kolapara and Rangabali Upazila (eastern region of Kolapara and central region of Rangabali Upazila), which concludes, these area are incompatible for deep aquifer groundwater development.

\section{Recommendation}

Interpreted result of the survey is prepared based on resistivity values from vertical electrical sounding at twenty one locations and lithology is estimated from seven monitoring well drilled by Center for Geoservices and Research (CGR). Compare to the extension of study area number of sounding points should be much more than just twenty one. At some places distances between two VES location is more than ten kilometers and extrapolated results may give much generalized and simplified result. As frequent change in subsurface lithology occurs within short distances, for impeccable and better-quality interpretation other geophysical methods such as resistivity logs, resistivity tomography and seismic facies analysis are necessary.

Water samples from higher resistivity zones of 2nd aquifer need to have chemical analysis for assurance of fresh water occurrence. 
Groundwater extraction from $3^{\text {rd }}$ aquifer should be avoided at whole Patharghta Upazila, eastern region of Kalapara and central region of Rangabali Upazila, because it shows low resistivity at respective depth and provide signature of salinity intrusion. Over extraction of ground water near low resistivity zones of 3rd aquifer need to be avoided because it can lead salinity to invade into nearer fresh water containing zone.

\section{References}

Aggarwal, P. K., Basu, A. R, Kulkarui, K. M., Froehlich, K., Tarafdar, S. A., Ali, M., Aluned, N. and Aluned, S. R. (2000). A Report on Isotope Hydrology of Groundwater in Bangladesh: Implications for Characterization and $M$ itigation of Arsenic in Groundwater. Work Performed within an IAEA- TCProject (BGD/8/016), 6lp.

Bugg, S.F., and Lloyd, J.W. (1976). A Study of Freshwater Lens Configuration in the Cayman Islands Using Resistivity Methods. Quarterly Journal of Engineering Geology and Hydrogeology, 9(4):291-302.

Imam, B. (2005). Energy Resources of Bangladesh, University Grants Commission, Dhaka.
Keary, P. and Brooks, M. (1984). An Introduction to Geophysical Exploration. Blackwell Scientific Publications, London, 296p.

Keller, G.V. and Frischnecht, F.C. (1996). Electrical M ethods in Geophysical Prospecting, Pergamon, Oxford.

Khan, A.E. Ireson, A., Kovats, S., M ojumder, S.K., Khusru, A., Rahman, A. and Vineis, P. (2011). Drinking Water Salinity and Maternal Health in Coastal Bangladesh: Implications of Climate Change. Environ Health Perspect. 119(9): 1328-1332.

Serres, Y.F. (1969). Resistivity prospecting in a United Nation Groundwater Study of Western Argentina. Geophysical Prospecting, 17 (449-467).

Woobaidullah, A.S.M., Ahmed, K.M. and Hasan, M.A. (1996). Electrical Resistivity and Hydrogeological Study for Saline Groundwater Investigation in M anda Thana, Naogaon District. Final Report, Bangladesh UGC Funded Research Project, 59p.

Zahid, A., Rahman, A., Hassan, M. R. and Ali M. H. (2016). Determining sources of groundwater salinity in the multi layered aquifer system of the Bengal delta, Bangladesh. BRAC University Journal, 2(37-51). 